\title{
Bolkar Dağlarının Acmaeoderini (Coleoptera: Buprestidae) Tribusu Türlerinin Tuzak Tercihleri ve Mevsimsel Dağglışları
}

\author{
Üzeyir ÇAĞLAR ${ }^{* *}$, Abdullah HASBENL ${ }^{2}$ \\ Sorumlu yazar: ucaglar@gazi.edu.tr \\ ${ }^{1}$ Gazi Üniversitesi, Sağlık Hizmetleri MYO, ANKARA \\ Orcid No: 0000-0002-8401-0155 / ucaglar@gazi.edu.tr \\ ${ }^{2}$ Gazi Üniversitesi, Fen Fakültesi, Biyoloji Bölümü, ANKARA \\ Orcid No: 0000-0002-2919-7594 / hasbenli@gazi.edu.tr
}

\begin{abstract}
Öz: Tuzak çeşitlerinin etkinliği; araştırma yöntemi, örnekleme, popülasyon yoğunluğu, mevsimsel dağılış gibi hususlarda böceklerin izlenmesi ve değerlendirilmesi için önemlidir. Bu çalışma ile Bolkar Dağlarında farklı yakalama yöntemleri kullanılarak yakalanan Acmaeoderini böcek türlerinin tuzak yöntemleri karşılaştırılması ve bu türlerin mevsimsel dağılışları değerlendirilmiştir. Çalışma alanında Acmaeoderini tribusuna ait toplam 815 örnek yakalanmıştır. Yakalanan bu örneklerden Acmaeodera cinsine ait 14 tür ve Acmaeoderella cinsine ait 9 tür tespit edilmiştir. Çalışmada Heydemann sınıflandırmasına göre 3 dominant, 3 subdominant, 10 rare ve 7 subrare tür tespit edilmiştir. Yakalama yöntemlerinden atrap yöntemi 572 örnek sayıs1 ilk sırada yer alırken, çukur tuzak yöntemi 1 örnek sayısı ile son sırada yer almıştır. Biyoçeşitlilik açısından atrap ile 22 tür, su tuzağı ile 12 tür, yapışkan tuzak ile 8 tür ve çukur tuzak ile 1 tür yakalanmıştır. Acmaeoderini tribusuna ait Nisan ayında 1, Mayıs ayında 187, Haziran ayında 257, Temmuz ayında 336, Ağustos ayında ise 34 örnek yakalanmıştır.
\end{abstract}

Anahtar Kelimeler: Buprestidae, Acmaeoderini, Bolkar Dağları, Biyoçeşitlilik, Tuzaklar

\section{Trap Preferences and Seasonal Distribution of Tribus Acmaeoderini (Coleoptera: Buprestidae) of Bolkar Mountains}

\begin{abstract}
The efficiency of trap varieties is an important factor for monitoring insects in terms of faunistic research, sampling, evaluation of population density, seasonal distribution criteria. In this study, the comparison of the trapping methods of the insect species in the Acmaeoderini tribus caught using different capture methods in Bolkar Mountains and the seasonal distribution of these species were evaluated. A total of 815 samples belonging to the Acmaeoderini tribus were caught in the study area. 14 species belonging to the Acmaeodera genus and 9 species belonging to the Acmaeoderella genus were determined from these samples. Within the scope of the study, 3 dominant, 3 subdominant, 10 rare and 7 subrare species were identified. Among the capture methods, the net trap method ranked first with 572 samples, while the pit trap method took the last place with 1 sample number. In terms of biodiversity, 22 species were caught with a net trap, 12 species with a water trap, 8 species with a sticky trap and 1 species with pit trap. Acmaeoderini tribus was caught 1 in April, 187 in May, 257 in June, 336 in July and 34 in August.
\end{abstract}

Keywords: Buprestidae, Acmaeoderini, Bolkar Mountains, Biodiversity, Traps

\section{Giriş}

Buprestidae familyası "Mücevher böcekleri” olarak bilinir ve hayvanlar aleminin tür sayısı bakımından en kalabalık sekizinci familyasıdır. Buprestidae familyasının Dünyada yaklaşık 15.000 türü bulunur (Bellamy, 2000). Acmaeoderini Kerremans, 1893 tribusunun Avustralya ve Okyanusya hariç Dünyada 4 subtribusu, 14 cinsi ve yaklaşık 700 türü bulunur (Bellamy, 
2008; Volkovitsh, 2008; Volkovitsh ve ark., 2015). Bu tribusun Palearktik bölgede 4 cinsi, Türkiye'de ise 2 cinsi bilinmektedir (Volkovitsh, 2006). Palearktik bölgede Acmaeodera Eschscholtz, 1829 cinsinin 9 altcinsi ve 98 türü (Volkovitsh, 1979, 2006), Acmaeoderella Cobos, 1955 cinsinin 6 altcinsi ve 120 'den fazla türü vardır (Volkovitsh, 1979, 2006, 2008; Bellamy 2008). Türkiye'de Acmaeodera cinsinin 27 türü, Acmaeoderella cinsinin 28 türü bulunur (Volkovitsh, 2006).

Buprestidae familyası kozmopolit olup tarım ve orman zararlıları olarak bilinen birçok türü içerir (Karagyan ve ark., 2004). Buprestidae familyası türlerinden meyve ağaçlarına, orman ağaçlarına, çalılar ve otsu bitkilere zarar veren birçok tür vardır. Türlerin çoğu, odun dokuyu tahrip edici zararlı larvalara (ksilofag) sahiptir (Lodos ve Tezcan, 1995; Sakalian ve Langourov, 2004; Ghobaria ve ark., 2013).

Buprestidae türlerinin koruma altına alınması fikri önemli ölçüde ilgi görmektedir, birçok tür, bazı ülkelerde kırmızı listeye alınmıştır, aynı zamanda buprestidler saprofilik böcek biyoçeşitliliğinin indikatörü olarak da kabul edilirler (Evans ve ark., 2007). Buprestidae türleri gelişimlerini ölü veya canlı yapraklı ağaçların kabukları altında veya çok yıllık odunsu bitkilerin odunsu saplarında tamamlarlar. (Muskovits ve Hegyessy, 2002).
Genel olarak böcekler gibi çeşitli yaşam biçimlerine sahip hayvanların envanterlerinin belirlenmesi için farklı yakalama yöntemlerinin kullanılması gereklidir (Lhoir ve ark., 2003). Dünyadaki pek çok böcek bilimci hem biyoçeşitlilik açısından hem de ekonomik olarak önemli olan yaşam biçimleriyle ve yaşam döngüsündeki yerleriyle böcekleri incelemek ve varlıklarını tespit etmek için türlerin davranış biçimleri ve aktivitelerini de dikkate alarak böcekleri yakalamak amaciyla renk tuzağı, malaise tuzağı, pencere tuzağı, su tuzağı ve yapışkan tuzak gibi farklı tuzaklar kullanmışlardır (Bellamy, 2000; Werner, 2002; Oliver ve ark., 2004; Sakalian ve Langrov, 2004; Bouget ve ark., 2008; Ghobaria ve ark., 2013; Varandi ve ark., 2018).

$\mathrm{Bu}$ çalışma 2005-2007 yılları arasında Bolkar dağlarında yapılan arazi çalışmalarında Acmaeoderini tribusuna ait türlerin biyoçeşitliliğini tespit etmek, Acmaeodera ve Acmaeoderella cinsi türlerinin yakalanmasında kullanılan farklı yakalama tekniklerinin verimliliğini karşılaştırmak ve tespit edilen türlerin zamana göre dağılımı ortaya koymak amacıyla yapılmıştır.

\section{Materyal ve Metot}

$\mathrm{Bu}$ çalışmada 2005-2007 yılları Nisan-Ağustos ayları arasında Bolkar Dağlarında İçel (Tarsus, Çamlıyayla, 
Erdemli, Silifke, Mut), Adana (Pozantı), Niğde (Ulukışla), Karaman (Merkez ve Ayrancı), Konya (Ereğli, Halkapınar) illeri içinde kalan bölgede Acmaeoderini tribusuna ait toplam 815 birey yakalanmıştır.

Çalışma bölgesinde deniz seviyesi ile $2000 \mathrm{~m}$ arasında değişik rakımlarda ve sulak alan, ormanlık, orman içi açıklık, derin vadiler, çeşitli zirai alanlar, odun depolama alanları ve stepler gibi değişik habitatlarda arazi çalışmaları yapılmıştır. Çalışma kapsamında böcek örneklerini yakalamak için atrap, su tuzağı, yapışkan tuzak ve çukur tuzak yöntemleri kullanılmıştır.

Arazi çalışması esnasında kullanılan bu tuzak yöntemlerinden su tuzağı ortalama 3 günlük süre sonunda, çukur tuzağ 1 ve yapışkan tuzağı ise ortalama 7 günlük süre sonunda kontrol edilmiş ve elde edilen örnekler \%70'lik etil alkollü kavanozlara konulmuştur. Atrap ile yakalanan örnekler ise o esnada \%70'lik etil alkollü kavanozlara konulmuştur.

Arazi çalışması sonunda Gazi Üniversitesi Zooloji Müze'sine getirilen örnekler uygun böcek iğneleri ile iğnelenerek müze materyali haline getirilmiştir. Teşhisi yapılan örnekler Müze database programına girilmiştir. Teşhisi yapılan ve tasnif kutularına yerleştirilen Acmaeoderini tribusuna ait böcekler Gazi Üniversitesi Zooloji Müzesi’nde (GUZM) muhafaza edilmektedir.

Tespit edilen türlerin baskınlık (yoğunluk) hesabı için Heydemann'ın sınıflandırması kullanılmıştır (Ghobaria ve ark. (2013)' göre). Bu siniflandırmada türlerin baskınlığını 5 gruba ayrılmıştır (Tablo 1).

Tablo 1. Heydemann sınıflandırması

\begin{tabular}{|ll|l}
\hline & $\begin{array}{l}\text { Eudominant türler (çok } \\
\text { baskin) }\end{array}$ & Yakalanan tüm örneklerin \% 30'undan fazlası \\
\hline $\mathbf{2}$ & Dominant türler (baskın) & Yakalanan tüm örneklerin \% 30 - \%10’u arası \\
\hline $\mathbf{3}$ & Subdominant türler (az baskın) & Yakalanan tüm örneklerin \% 10 - \%5'i arası \\
\hline $\mathbf{4}$ & Rare türler (nadir) & Yakalanan tüm örneklerin \% 5 - \%1'i arası \\
\hline $\mathbf{5}$ & Subrare türler (çok nadir) & Yakalanan tüm örneklerin \% 1'den azı \\
\hline
\end{tabular}

3. Araştırma Sonuçları

Yapılan bu çalışma sonucunda Acmaeodera cinsine ait 14 tür, Acmaeoderella cinsine ait 9 tür tespit edilmiştir. Türlerin baskınlık durumları
Heydemann sinıflandırmasına göre değerlendirilmiş olup 3 dominant (baskın), 3 subdominant (az baskın), 10 rare (nadir) ve 7 subrare (çok nadir) tür tespit edilmiştir (Tablo 2). 
Tablo 2. Acmaeoderini tribusu tür listesi ve değerler tablosu

\begin{tabular}{|c|c|c|c|c|c|}
\hline & Tür Adı & $\begin{array}{l}\text { Yakalama } \\
\text { Tekniği } *\end{array}$ & $\begin{array}{l}\text { Örnek } \\
\text { sayısı }\end{array}$ & $\begin{array}{l}\text { Yoğunluk } \\
\text { yüzdesi }\end{array}$ & $\begin{array}{l}\text { Baskınlık } \\
\text { durumu }\end{array}$ \\
\hline 1 & Acmaeodera (Acmaeodera) brevipes Kiesenwetter, 1858 & $\mathrm{~A}, \mathrm{~S}$ & 167 & $\% 20.49$ & Dominant \\
\hline 2 & Acmaeodera (Acmaeodera) distigma Obenberger, 1924 & $\mathrm{~A}, \mathrm{~S}$ & 129 & $\% 15.82$ & Dominant \\
\hline 3 & Acmaeodera (Acmaeodera) flavolineata Laporte \& Gory, 1835 & $\mathrm{~A}, \mathrm{~S}$ & 54 & $\% 6.62$ & Subdominant \\
\hline 4 & Acmaeodera (Acmaeodera) pilosellae (Bonelli, 1812) & $\mathrm{A}, \mathrm{S}$ & 9 & $\% 1.10$ & Rare \\
\hline 5 & Acmaeodera (Acmaeodera) xanthelytra (Obenberger, 1940) & A,S & 13 & $\% 1.15$ & Rare \\
\hline 6 & Acmaeodera (Acmaeotethya) crinita Spinola, 1838 & A & 9 & $\% 1.10$ & Rare \\
\hline 7 & Acmaeodera (Acmaeotethya) degener (Scopoli, 1763) & $\mathrm{A}, \mathrm{Y}$ & 4 & $\% 0.49$ & Subrare \\
\hline 8 & Acmaeodera (Acmaeotethya) ottomana (Frivaldszky, 1837) & A & 8 & $\% 0.98$ & Subrare \\
\hline 9 & Acmaeodera (Acmaeotethya) quadrifasciata (Rossi, 1790) & $\mathrm{A}, \mathrm{S}$ & 28 & $\% 3.43$ & Rare \\
\hline 10 & $\begin{array}{l}\text { Acmaeodera (Acmaeotethya) quadrizonata Abeille de Perrin, } \\
1891\end{array}$ & A & 2 & $\% 0.24$ & Subrare \\
\hline 11 & Acmaeodera (Acmaeotethya) saxicola Spinola, 1838 & $\mathrm{~A}, \mathrm{~S}, \mathrm{Y}$ & 34 & $\% 4.17$ & Rare \\
\hline 12 & Acmaeodera (Palaeotethya) bipunctata (Olivier, 1790) & $\mathrm{A}, \mathrm{S}, \mathrm{Y}$ & 149 & $\% 18.28$ & Dominant \\
\hline 13 & Acmaeodera (Palaeotethya) quadrifaria Baudi di Selve, 1870 & $\mathrm{Y}$ & 1 & $\% 0.12$ & Subrare \\
\hline 14 & Acmaeodera sp. 1 & $\mathrm{~A}, \mathrm{~S}$ & 11 & $\% 1.34$ & Rare \\
\hline 15 & Acmaeoderella (Carininota) farinosa (Reiche, 1856) & A,S,Y,Ç & 55 & $\% 6.74$ & Subdominant \\
\hline 16 & $\begin{array}{l}\text { Acmaeoderella (Carininota) flavofasciata (Piller \& } \\
\text { Mitterpacher, 1783) }\end{array}$ & $\underline{\mathrm{A}, \mathrm{S}}$ & $\underline{15}$ & $\% 1.84$ & Rare \\
\hline 17 & Acmaeoderella (Carininota) mimonti (Boieldieu,1865) & A & 25 & $\% 3.06$ & Rare \\
\hline 18 & Acmaeoderella (Carininota) vetusta (Menetries, 1983) & $\mathrm{A}, \mathrm{Y}$ & 4 & $\% 0.49$ & Subrare \\
\hline 19 & Acmaeoderella (Carininota) villosula (Steven,1830) & A & 35 & $\% 4.29$ & Rare \\
\hline 20 & Acmaeoderella (Liogastria) chrysanthemi (Chevrolat, 1854) & $\underline{\mathrm{A}, \mathrm{S}}$ & $\underline{42}$ & $\% 5.15$ & Subdominant \\
\hline 21 & Acmaeoderella (Omphalothorax) adspersula (Illiger, 1803) & $\mathrm{A}, \mathrm{Y}$ & 8 & $\% 0.98$ & Subrare \\
\hline 22 & Acmaeoderella (Omphalothorax) despecta (Baudi, 1870) & A & 10 & $\% 1.22$ & Rare \\
\hline 23 & $\begin{array}{l}\text { Acmaeoderella (Omphalothorax) longissima (Abeille de Perrin, } \\
\text { 1904) }\end{array}$ & $\mathrm{A}, \mathrm{Y}$ & 3 & $\% 0.36$ & Subrare \\
\hline
\end{tabular}

* $\mathrm{A}=$ Atrap, $\mathrm{S}=\mathrm{Su}$ tuzağ $\breve{1}, \mathrm{Y}=$ Yapışkan tuzak, $\mathrm{C}=$ Çukur tuzak

Elde edilen örneklerin yakalanma yöntemlerine göre oransal dağılımları pasta grafik şeklinde gösterilmiştir. Buna göre atrap ile yakalama yönteminde 572 örnek, su tuzağ1 ile yakalama yönteminde 207 örnek, yapışkan tuzak ile yakalama yönteminde 35 örnek, çukur tuzağı ile yakalama yönteminde 1 örnek yakalanmıştır (Şekil 1). 


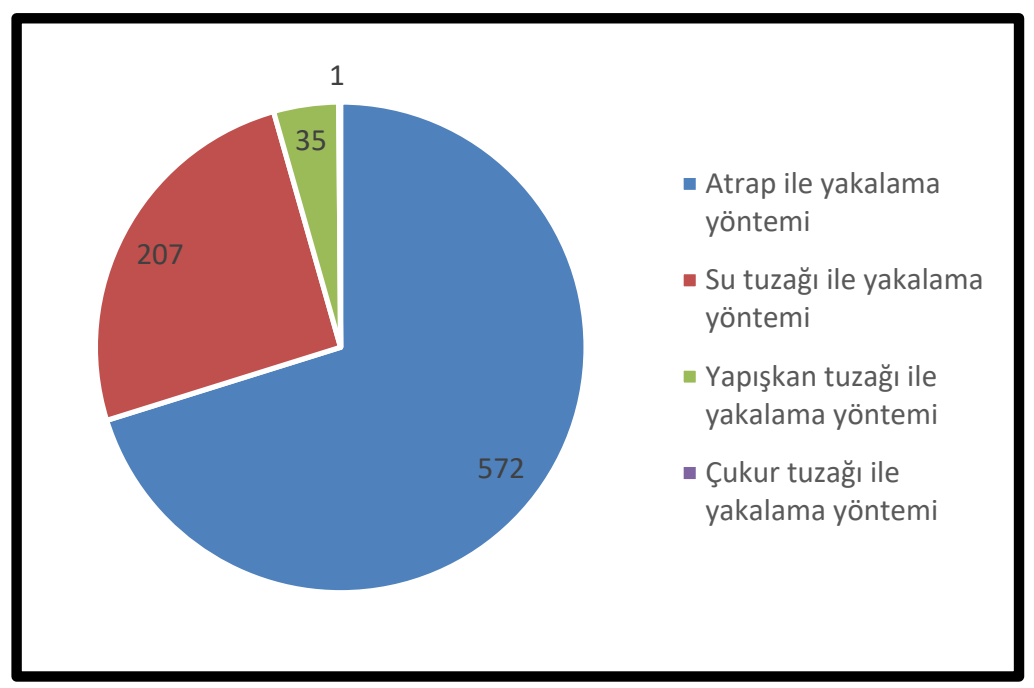

Şekil 1. Yakalama yöntemlerine göre örnek sayısı grafiği

$\mathrm{Bu}$ çalışma kapsamında kullanılan her bir yöntem için yakalanan tür sayılarının değerlendirmesi pasta grafik şeklinde gösterilmiştir.

Atrap ile yakalanan tür sayısı 22 olup tür çeşitliliği bakımından en fazla yakalama yöntemi olarak tespit edilmiştir. $\mathrm{Su}$ tuzağı ile 12 tür yakalanmıştır. Yapışkan tuzak yöntemiyle ise 8 tür yakalanmıştır. Son olarak çukur tuzağında yakalanan tür sayısı 1 olarak tespit edilmiştir (Şekil 2).

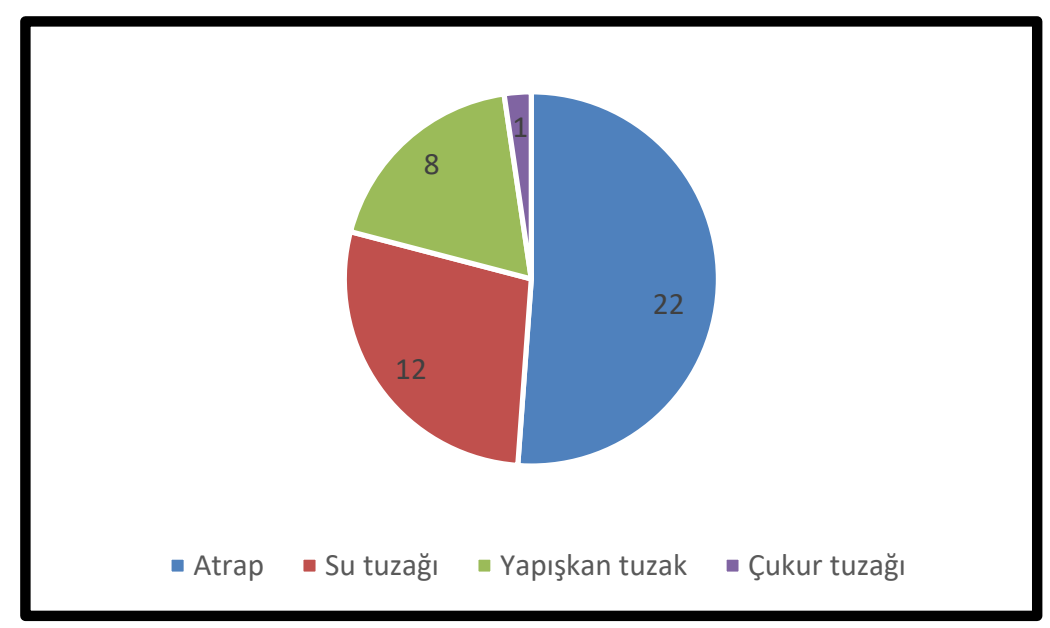

Şekil 2.Yakalama yöntemlerine göre tür sayısı grafiği

Çalışma kapsamında yakalanan örnekleri zamana göre dağılımı grafik şeklinde gösterilmiştir ve Acmaeoderini tribusuna ait Nisan ayında 1, Mayıs ayında
187, Haziran ayında 257, Temmuz ayında 336, Ağustos ayında ise 34 örnek yakalanmıştır (Şekil 3). 


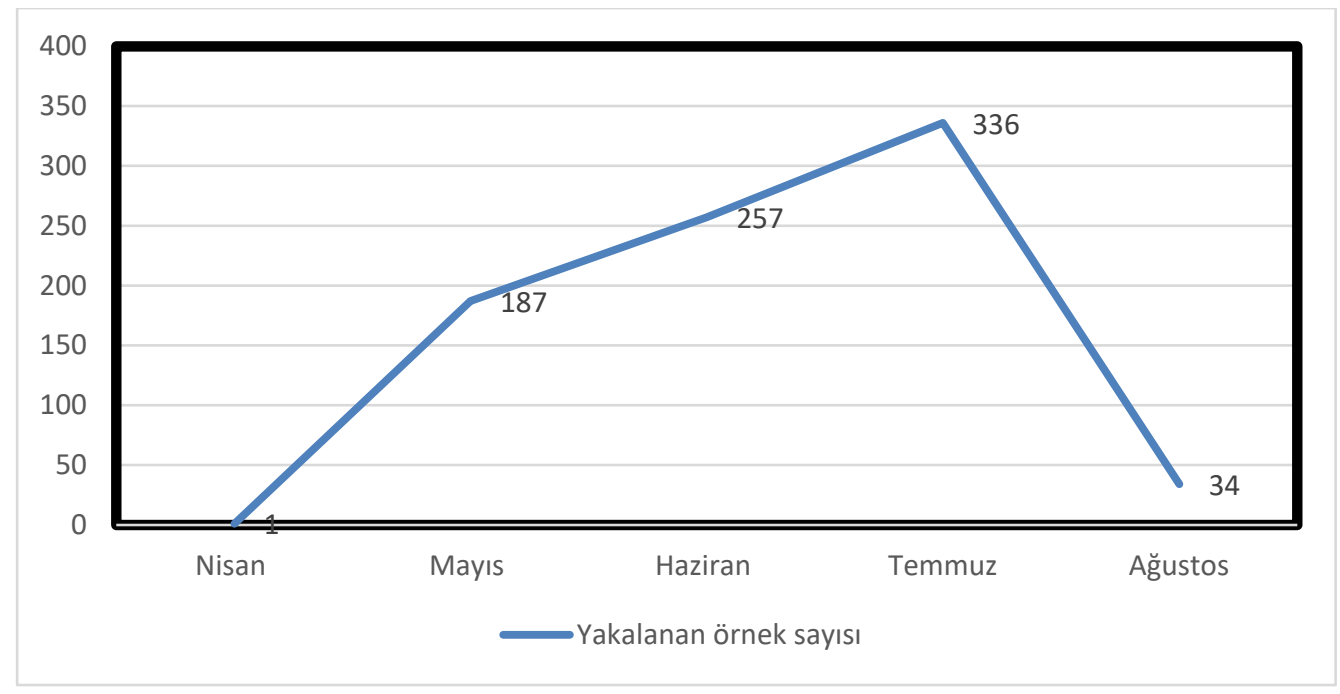

Şekil 3. Zamana göre örnek sayısı dağılımı grafiği

\section{Tartışma}

Böceklerin yakalanması için farklı tuzak yöntemlerinin kullanılması arazi çalışmalarının en önemli unsurları olarak kabul edilir (Bouget ve ark., 2008). Bu çalışmadaki verilerde farklı tuzak yöntemlerinin faunistik, biyoçeşitlilik ve ekolojik çalışmalar için kullanılabileceğini ortaya koymuştur.

Arazi çalışmalarında kullanılan yakalama yöntemleri örnek sayısı bakımından kıyaslandığında atrap ile yakalama yöntemi 572 örnek ile ilk sırada, su tuzağı ile yakalama yönteminde 207 örnek ile ikinci sırada, yapışkan tuzak ile yakalama yöntemi 35 örnek ile üçüncü sırada, çukur tuzağı ile yakalama yöntemi ise 1 örnek ile son sırada yer almıştır. Atrap ile yakalama yöntemi aktif yakalama tekniği olarak bilinir ve örnek yakalama sayısı bakımından ilk sırada olması normaldir. Pasif yakalama yöntemleri içinde ise örnek sayısı bakımından su tuzağı yöntemi en başarılı yakalama yöntemi olarak tespit edilmiştir.

$\mathrm{Bu}$ çalışma kapsamında kullanılan tuzak yöntemleri ile biyoçeşitlilik ilişkisi değerlendirildiğinde aktif yakalama yöntemi olan atrap ile yakalanan tür sayısı 22 olup tür çeşitliliği bakımından ilk sırada yer almaktadır. Pasif yakalama yöntemleri içinde su tuzağı ile yakalanan tür sayısı 12 olup tür sayısı bakımından ikinci sıradadır, yapışkan tuzak ile yakalanan tür sayısı 8 , çukur tuzağı ile yakalanan tür sayısı 1 olarak tespit edilmiştir.

Elde edilen türler yakalama metotlarına göre değerlendirildiğinde sadece atrap ile yakalanan tür sayısı 6, sadece yapışkan tuzak ile yakalanan (Acmaeodera (Acmaeotethya) quadrifasciata (Rossi, 1790)) tür sayısı 1'dir. İki tuzak yöntemi ile yakalanan türlere bakıldığında atrap ve su tuzağı ile yakalanan tür sayısı 9, atrap ve yapışkan tuzak ile yakalanan tür sayısı 4 'dür. 
Üç yöntem ile yakalanan türlere bakıldığında atrap, su tuzağı ve yapışkan tuzak ile yakalanan tür sayısı 2'dir. Dört yöntem ile yakalanan (Acmaeoderella (Carininota) farinosa (Reiche, 1856)) tür sayısı 1'dir. Bu veriler yapılacak olan arazi çalışmalarında tuzak yöntemlerinin tür çeşitliliğinin artmasına katkı sağlayacağını açıkça ortaya koymaktadır.

Tezcan, Nisan ve Ağustos ayları arasında yapılan arazi çalışmalarında Acmaeodera ve Acmaeoderella cinlerine ait türlerin en fazla örnek sayısının mayıs ve haziran aylarında görüldüğünü belirtmiştir (Tezcan, 1995). Bu çalışma ise zamanlama olarak değerlendirildiğinde Acmaeoderini tribusuna ait yakalanan örnek sayıları nisan ayında 1, Mayıs ayında 187, Haziran ayında 257, Temmuz ayında 336, Ağustos ayında ise 34 örnek olarak tespit edilmiştir. $\mathrm{Bu}$ sonuçlara göre örnek sayısı bakımında en verimli zaman diliminin 336 örnek ile (toplam örnek sayısının \% 41.22'si) Temmuz ayı olduğu görülmektedir.

Türlerin baskınlı durumları Heydemann sinıflandırmasına göre değerlendirilmiş olup 3 tür dominant (toplam tür sayısının \% 13’ü), 3 tür subdominant (toplam tür sayısının \% 13’ü), 10 tür rare (toplam tür sayısın \% 43'ü) ve 7 tür subrare (toplam tür sayısının \% 30’u) olarak tespit edilmiştir. Buna göre rare (nadir) tür sayısı yüzdesi ilk sırada yer almaktadır.

Araştırma kapsamında tespit Acmaeodera cinsine ait 14 tür bu cinsin Türkiye'den bilinen 27 türüne kıyaslandığında $\% \quad 52$ 'sine karşılık gelmektedir, Acmaeoderella cinsine ait 9 tür bu cinsin Türkiye'den bilinen 28 türüne kıyaslandığında $\quad \% \quad 32$ 'sine karşılık gelmektedir. Çalışma bölgesinin Türkiye'deki coğrafik oranı kıyaslandığında bu oran oldukça küçüktür. Buda Bolkar Dağları Acmaeoderini tribusu biyoçeşitliliğinin oldukça yüksek olduğu sonucunu ortaya koymaktadir.

Bu çalışma birinci yazarın Doktora tezinin bir parçasıdır ve 20. Ulusal Biyoloji Kongresi (2010)'de poster bildiri olarak sunulmuştur.

\section{Kaynaklar}

Bellamy CL (2000). Buprestidae (Coleoptera, Buprestoidea). Dâures - biodiversity of the Brandberg Massif, Namibia. Cimbebasia Memoir 9: 185-191.

Bellamy CL (2008). A World Catalogue and Bibliography of the Jewel Beetles (Coleoptera: Buprestoidea), Volume 1: Introduction; Fossil Taxa; Schizopodidae; Buprestidae: Julodinae Chrysochroinae: Poecilonotini. Sofia-Moscow, Pensoft Publishers. 625 pp.

Bouget C, Brustel H, Bri A, Noblecourt T (2008). Sampling saproxylic beetles with window flight traps: methodological insights. Rev Ecol (Terre Vie), suppt. 10. 
Evans HF, Moraal LG, Pajeres JA (2007). Biology, ecology and economic importance of Buprestidae and Cerambycidae. In: Lieutier F, Day KR, Battisti A, Gregoire J-C, Evans HF (eds) Bark and wood boring insects in living trees in Europe, a synthesis. Springer, Dordrecht, 447-474.

Ghobaria H, Nozarib J, Kalashian M (2013). Investigation of Buprestidae diversity by using different traps in rangelands of Kurdistan province-Iran. Soaj Entomological Studies 2: 57-61.

Karagyan G, Kuznetsova VG, Lachowska D (2004). New cytogenetic data on Armenian Buprestids (Coleoptera, Buprestidae) with a discussion of karyotype variation within the family. Folia Biologica (Kraków) 52(3-4): 151-158.

Lhoir J, Fagot J, Thieren Y, Wilson G (2003). Efficacité du piégeage, par les méthodesclassiques, des Coléoptèressaproxyliques en régionWallonne (Belgique). Notes fauniques de Gembloux 50: 4961.

Lodos N, Tezcan S (1995). Türkiye Entomolojisi V: Buprestidae" Entomoloji Derneği Yayınları, 8: 1138.

Muskovits J, Hegyessy G (2002). Magyarország díszbogarai. Jewel beetles of Hungary (Coleoptera: Buprestidae). Grafon Kiado Nagykovacsi 1-404.

Oliver JB, Fare D, Youssef N, Klingeman W (2004). A survey trap to monitor adult flat headed borer activity in nurseries, pp. H-1. In M. E. Lewis [ed.], Proc. 26th Ann. University-Wide Res. Sympos Teennessee State University 6-8 April 2004. Nashville TN.

Sakalian V, Langourov M (2004). Colour trap a method for distributional and ecological investigations of Buprestidae (Coleoptera). Acta Societatis Zoologicae Bohemicae 68: 53-59.

Tezcan S (1995). Contribution to the study of the genere Acmaeodera Eschscholtz and Acmaeoderella Cobos (Coleoptera, Buprestidae, Acmaeoderinae) of Turkey. Türkiye Entomoloji Dergisi 19(1): 69-79.

Varandi HB, Kalashian M, Barari H, Taleshi SAR (2018). The diversity of wood-boring beetles caught by different traps in northern forests of Iran. Tropical Drylands 2(2): 65-74.

Volkovitsh MG (1979). Review of the Palaearctic groups of jewel beetles of the tribe Acmaeoderini (Coleoptera, Buprestidae). Entomologicheskoe Obozrenie 58(2): 333-354.

Volkovitsh MG (2006). New nomenclatorial and taxonomic acts, and comments. Buprestidae: Polycestinae and Buprestinae. pp. 56-58; Catalogue. Buprestidae: Polycestinae. pp. 330-342. In: Löbl I., A. Smetana (Eds). Catalogue of Palaearctic Coleoptera. Volume 3. - Scarabaeoidea - Scirtoidea - Dascilloidea - Buprestoidea - Byrrhoidea. Apollo Books, Stenstrup, 690 pp.

Volkovitsh MG (2008). A review of the Buprestid genus Cochinchinula Volk. with description of new taxa from Thailand, and notes on the composition and classification of the tribe Acmaeoderini (Coleoptera, Buprestidae, Polycestinae.). Entomological Review, 88(3): 329-349.

Volkovitsh MG, Sakalian V, Georgiev G (2015). A Checklist and a Key to the Taxa of the Subfamily Polycestinae Lacordaire, 1857 (Coleoptera: Buprestidae) in Bulgaria. Acta zoologica bulgarica 67(4): 471-478.

Werner RA (2002). Effect of ecosystem disturbance on diversity of bark and wood-boring beetles (Coleoptera: Scolytidae, Buprestidae, Cerambycidae) in white spruce (picea gluca (Moench) Voss) ecosystem of Alaska. Res. Pap. PNW-RP-546. U.S. Department of Agriculture. Forest Service, Pacific Northwest Research Station. Portland, OR. 